\title{
Jumpstarting Cross-Discipline Collaboration in Undergraduate Social Work Education
}

\author{
Cyndi Amato \\ Shelley Cohen Konrad \\ Lane W. Clarke \\ Caryn Husman \\ Audrey Bartholomew \\ Caroline Beals
}

\begin{abstract}
This paper examines the integration of undergraduate teacher education students into interprofessional activities with social work and pre-occupational therapy undergraduates. Like health professionals, school-based professionals work across disciplines daily and come together for critical decision-making on behalf of vulnerable and special needs students. Although evidenced-based pedagogy in interprofessional education (IPE) has become common in graduate and professional health education, less is known about its implementation in undergraduate education and with non-health-related disciplines. This article describes a 2-year interprofessional undergraduate simulation project with social work, teacher education, and pre-occupational studies students working prospectively in a K-12 school setting. Survey data found that students gained confidence in their disciplinary roles as well as in their abilities to communicate and collaborate effectively as a result of participation in the school-based simulation and related activities. The project highlighted the benefits of situating theory-driven undergraduate interprofessional learning in settings beyond healthcare and the need for developing assessment tools inclusive of undergraduates and relevant to a range of workforce environments.
\end{abstract}

Keywords: Simulation, interprofessional education, collaboration, undergraduate social work education, occupational therapy

Interprofessional education (IPE) has become a common, evidence-based pedagogy in the education of health and social care professionals. Interprofessional education is defined as when students from two or more professions participate in interactive, shared learning opportunities with the goal of improving future collaborative practice in a host of settings (World Health Organization, 2010). When to infuse interprofessional practice competencies into curriculum is still a subject of debate; however, there is a body of literature suggesting that the earlier students are introduced to IPE, the more engaged they become with collaborative learning throughout their educational programs (Pardue, 2013; Ruebling et al., 2014). Early cross-professional opportunities foster students' relational confidence, a key attribute of communication and team-based skills. Frequent interprofessional interaction through curricular and extracurricular activities promotes a

Cyndi Amato, MSW, Assistant Clinical Professor, BSW Program Director, School of Social Work; Shelley Cohen Konrad, PhD, LCSW, FNAP, Professor, Director School of Social Work, Director Center for Excellence in Collaborative Education; Lane W. Clarke, PhD, Associate Professor, Education Department; Caryn Husman, MS, OTR/L, Associate Clinical Professor, Health, Wellness and Occupational Studies Program Director; Audrey Bartholomew, PhD, Associate Professor, Chair of Education Department; Caroline Beals, MS, OTR/L, Assistant Professor, Department of Occupational Therapy, University of New England. 
culture of psychological safety, which is the belief that one can offer ideas, alternative perspectives or risk making a mistake without fear of negative repercussion. Studies indicate that health professions students' early zeal for teamwork and collaboration ebbs over the course of their education (Pardue, 2013; Ruebling et al., 2014). Students engaged in interprofessional interaction throughout their studies - particularly immersive activities relevant to their future practice - maintain positivity about their skills for collaborative practice and teamwork (McFadyen et al., 2010; Pardue, 2013).

The importance of interprofessional health professions education is well-validated (Gray et al., 2015; Howell \& Cleary, 2001; Johnson, 2017). Large-scale reviews examining the effectiveness of IPE offer evidence for improved team-based and communication skills, confidence, collegiality, and mutual respect amongst students. A growing body of findings indicate that those exposed to IPE are better prepared for team-based collaborative practice (Cohen Konrad et al., 2017; Cox et al., 2016). In 2016, the national Interprofessional Education Collaborative published an update of its 2011 collaborative competencies report broadening its reach "to work together across disciplines, organizations, and sectors on innovative strategies to improve population health" (IPEC, 2016, p. 4). IPEC's expansion of team membership opened opportunities for teacher educators, among others, to engage in collaborative learning across fields beyond healthcare.

Though the benefits of IPE have been supported in academic literature, full integration into health professions curriculum has been slow to develop. Formal training is commonly conducted in academic silos with knowledge, skills, attitudes, and approaches reflective of single-discipline perspectives. Although such pedagogy is necessary for learners to hone their unique professional skills, absence of instruction in collaborative practice leaves graduates underprepared for the contemporary team-based workplace. Undergraduate training for disciplines outside of the health professions is similarly uniprofessional with little or no curriculum devoted to intersectional roles and responsibilities. For K-12 teachers, who interact with multiple fields of practice in schools and other educational environments, lack of collaborative learning opportunities leaves a gap in their formal training.

Collaborative learning opportunities at our university are well integrated into social work and occupational therapy (OT) curriculum but are just emerging in teacher training curriculum and practice. Opportunities to advance student collaborative learning in preparation for work in school-related settings are vast given the varying professionals employed to attend to increasingly complex student needs (e. g. teachers, social workers, occupational therapists, school nurses, psychological examiners, speech and language practitioners, and system administrators). To be effective in contemporary public education, teachers need wide-ranging skills as well as appreciation for the impacts of adversity and sociocultural factors on children's learning (McMahon et al., 2012). Collaborative learning alerts future teachers to the collaborative capacities of other professionals, including social workers and OTs who are often employed within school settings (Stone \& Charles, 2018).

This paper describes benefits, challenges, and theoretical insights learned from a twoyear undergraduate interprofessional simulation project that brought together social work, 
pre-occupational therapy, and teacher education students. We detail the context and integration of selected learning theories and how these and critical teaching methods incorporate IPEC (2016) competencies while simultaneously meeting each professions' accreditation standards and ethical codes (See Table 1). Exemplars of student activities and case scenarios will be offered to illustrate the implementation of cross-disciplinary learning and its benefits and challenges. The paper will conclude with a discussion of recommendations and implications for undergraduate collaborative shared learning organized around common educational goals that aim to improve the greater good.

\section{Interprofessional Competencies and Learning Theories}

The U.S. Interprofessional Education Collaborative (IPEC) articulates foundational competencies for collaborative practice considered relevant to be an effective member of any team in any setting. Competencies focus on how best practice is conducted across content areas. IPEC collaborative competencies include: Competency 1: Values and Ethics for Interprofessional Practice; Competency 2: Knowledge of Other's Roles and Responsibilities; Competency 3: Interprofessional Communication and Competency; and 4: Teams and Teamwork (IPEC, 2016).

According to Reeves and Hean (2013), collaborative learning models generally reflect a blend of education, relational, and social engagement theories to achieve desired educational outcomes. Kolb's (1984) experiential learning theory, a 4-tier scaffolded learning process, is a useful and relevant framework to guide design of IPE undergraduate experiences. The first tier, concrete experience, begins with the presentation of new material. The second tier, reflective observation, has students individually and collectively observe and ponder new material from a critical standpoint. Tier three, abstract conceptualization, prompts students to be curious about new material, asking questions within the confines of a psychologically safe learning environment. The final tier, active experimentation, has students applying their new learning in direct, simulated or real-world activities.

Attitudinal change instigated through affective learning is another critical component of interprofessional education. Students enter health, social care, and other fields of practice with presumptions and stereotypes about other professions and future clients, and the problems they face. Contact hypothesis theory (Hewstone \& Brown, 1986) informs pedagogy aimed at changing attitudes and opening channels of active interchange, curiosity, and iterative learning. Facilitation of experiential inquiry is critical to creating an environment of mutual respect and trust.

Relational learning theory informs the context in which students from varying backgrounds and disciplines learn with and from each other. According to Browning and Solomon (2006), relational learning methods attend to how information is shared and transformed. Learning activities are designed so that students have opportunities to practice together, tolerate differences, apply diverse knowledge to problem-solve, and then build capacities to address and manage ethical dilemmas and difficult encounters. Within a relational learning paradigm, collaborative competencies are readily translated into learning outcomes as they promote mutual respect, responsive and reflective practice, and 
person-centered care. Cultural humility is a critical aspect of relational learning. Browning and Solomon (2006) describe cultural humility as willingness to place a foot in both worlds - the world of the patient/client/family as well as the worlds of differing workplace disciplines.

Altogether, these learning theories informed the interprofessional simulation project aligning it with overarching principles of collaborative practice. They provided a coherent framework for designing, implementing and assessing undergraduate learning activities. They guided the development of a collaborative learning environment where students felt safe to make mistakes, address differences, deal with complexities, and learn how to effectively communicate with others.

\section{Social Work Students}

Collaborative learning opportunities introduce bachelor's in social work (BSW) students to elements of interprofessional inquiry, collaborative generalist practice, teamwork, and exposure to disciplines they will encounter in future workplace settings. Paraphrasing Bronstein (2003), interdisciplinary and collaborative learning promotes the achievement of goals that cannot be reached when individual disciplines act solely on their own. For BSW students, learning with other disciplines enriches foundational knowledge and builds skills for integrated micro, mezzo, and macro practice.

The National Association of Social Work (NASW) Code of Ethics delineates social workers' ethical obligation to cross-professional cooperative, respectful, and collaborative exchange to fully serve the best interests and needs of clients (NASW, 2017). Principles inherent in both the National Association of Social Workers (NASW, 2017) and the International Federation of Social Workers (IFSW, 2018) code of ethics empower social workers to be collaborative practitioners, maintain ethical responsibilities to colleagues, and transcend disciplinary boundaries. The IPEC (2016) core competencies complement social work's ethical standards by identifying the obligation to work together across all levels of practice.

Specific to the school setting, the NASW (2012) School Social Work Standards empowers school social workers to be leaders in "developing a positive school climate" while working collaboratively with administration, colleagues, families, and others to "increase accessibility and effectiveness of services" (p. 13). Experiential interprofessional opportunities elevate student's understanding of how communication and collaboration enhances the quality of life of their clients.

Social work education emphasizes the intersectional nature of human problems and thus the implicit need for interdisciplinary, cross-sector collaboration. Yet while in principle social workers value "interdisciplinary collaboration and multidisciplinary practices, they are rarely paired with other professions in the classroom or intentionally taught about counterparts' roles and expertise over the course of their baccalaureate and graduate education" (Rubin et al., 2017, p. 4). According to Rubin and colleagues (2017), "IPEC core competencies resonate with the vision of social work education and the core learning outcomes prescribed for students" (p. 20). They align with the tenets of generalist social work education and conform to the Commission on Accreditation (COA) of the 
Council on Social Work Education's (CSWE, 2015) nine Education Policy and Accreditation Standards (EPAS) competencies (CSWE, 2015). Wedding Integrating these core competencies in the generalist social work curriculum ensures quality and continuous improvement of accredited social work programs.

EPAS Competency 1 and IPEC Competency 1 (Values/Ethics for Interprofessional Practice) deepen social work students' understanding of their responsibility to engage in ethical and professional behavior in their coursework and in the field. They reinforce social work as a value-based profession, one that elevates human dignity and calls upon social workers' ethical responsibility to challenge barriers to social inclusion. The key tenets of cultural responsiveness are woven throughout IPEC's Core Competencies aligning with EPAS Competency 2 which engages students in learning about diversity and difference, asking them to reflect upon assumptions that impede effective service and disrupts the formation of healthy, productive cross-professional collaboration.

EPAS 8 explicitly addresses the critical nature of building skills for collaborative social work practice. It identifies comparable competencies to those cited by IPEC and emphasizes the value and "importance of interprofessional teamwork and communication in interventions, recognizing that beneficial outcomes may require interdisciplinary, interprofessional, and inter-organizational collaboration" (CSWE, 2015, p. 9). Curriculum inclusive of these ideals teaches students critical skills for health-promotion and equitable care.

\section{Pre-Occupational Therapy Students}

The American Council for Occupational Therapy Education (ACOTE) and The American Occupational Therapy Association (AOTA) goals and ethics similarly align with IPEC (2016) Core Competencies. Like social work EPAS Competency 8, ACOTE Standard B requires OT programs to prepare students to understand the roles and responsibilities of other team members and navigate team dynamics to provide patient and population-centered care (AOTA, 2018). OT philosophy is consistent with IPE's foundation in person/patient-centered care. AOTA recognizes that OT practitioners must be prepared to collaborate across professions to provide high quality services (AOTA, 2015).

Respect for human dignity, diversity and difference is at the core of OT's professional Code of Ethics (COE, AOTA, 2015). Mutual respect is an ethical standard for practice inclusive of clients, families, populations, and other professions. In combination, OT accreditation standards and their COE conforms to the principles and aims of IPEC's core competencies, seeking commonalities across ethics, values, skills, and practices.

IPE methodology is steadily emerging within the field of graduate-level OT professional training with documented benefits, including improvement in role clarification (Halle et al., 2019; Mellor et al., 2013; Shoemaker et al., 2014), increased value for the contributions of other professionals, and teamwork (Morrell et al., 2018; Moyers et al., 2014). Undergraduates who plan to pursue a professional OT degree, however, have limited IPE opportunities to develop foundational collaborative practice attitudes and skills. 
OT curricula is required to integrate learning opportunities that facilitate both understanding and active application of interprofessional collaborative skills (AOTA, 2015). Contact hypothesis theory (Hewstone \& Brown, 1986) offers useful guidance as it calls for scaffolded exposure to experiential learning opportunities that specifically target novice learners' learning levels, cognitive development and nascent professional identities. OT faculty systematically increase students' engagement with collaborative competencies through thoughtful exposure, repetition, assessment, and application of collaborative encounters, building students' disciplinary confidence and their teamwork skills.

In educational settings, OT's facilitate academic success by ameliorating developmental and organizational challenges faced by children with and without disabilities (AOTA, 2011). They consult with teachers to adapt curriculum and technology to effectively produce student learning. According to Pardue (2013), undergraduate IPE learning for pre-occupational therapy students "imparts an academic foundation whereby IPE learning contributes to future graduate study" (p. 98).

\section{Teacher Education Students}

Integration of interprofessional core competencies for collaborative practice is equally important for teacher education curriculum, yet, unlike the other two professions, teacher education does not use IPE competencies. However, in practice, teachers communicate across disciplines, particularly as members of pupil evaluation and other problem-solving teams. Teachers collaborate with parents, community and social service personnel, law enforcement, and a range of health professionals to ensure that students are receiving appropriate education, especially those who have disabilities and medical and behavioral health conditions (D'Agastino, 2013). According to McMahon and colleagues (2012), an effective teacher in today's educational climate requires skills and understanding of how to work within a professional community - much like a health professional. These authors emphasize the importance of training teachers to work in community and collaborative settings with colleagues from a range of professions and disciplines.

While interprofessional education is not specifically named in teacher education accreditation standards, collaborative approaches are validated by the Interstate Teacher Assessment and Support Consortium Standards. (InTASC, Council of Chief State School Officers [CCSTO], 2013). Many of these standards incorporate the ideals of the IPEC (2016) Competencies, and collaboration with professionals, families, communities and learners is threaded throughout the document. The introduction to the InTASC Standards, a "New Vision of Teaching and Improved Student Achievement," articulates a less isolated expectation for teachers "just as collaboration among learners improves student learning, we know that collaboration among teachers improves practice (CCSTO, 2013, p. 4). Standard 10, Leadership and Collaboration, specifically links teaching to interdisciplinary practice, stating that "the teacher seeks appropriate leadership roles and opportunities to take responsibility for student learning, to collaborate with learners, families, colleagues, other school professionals, and community members to ensure learner growth, and to advance the profession" (CCSTO, p. 45). Knowledge and application of interprofessional competencies have much to offer future teachers who will naturally interact with other professional fields of practice to improve children's academic and behavioral success. 
Preparing teachers with strengths in teamwork, self-efficacy, communication, problemsolving, and shared decision-making is compatible with the values of the education profession.

Despite the many ways in which teachers are called upon to collaborate with others, teacher education has yet to adopt IPE competencies or cross-professional methods as common pedagogical practice. A study was conducted in 2019 to learn whether K-12 personnel had exposure to interprofessional collaborative concepts in their preparatory education (Clark et al., 2019). It found that school personnel understand interprofessional collaboration to be valuable for student success, effective teaching, and improvements in school culture. Yet, while teachers recognize the benefits of integrated, collaborative practice in education, few school personnel receive explicit continuing education or training in teamwork competencies and IPE is absent from teacher education curriculum (Clark et al., 2019).

Research investigating interprofessional content and methodologies in teacher education points to its advantages. Interprofessional shared learning experiences have been shown to improve the preparation and quality of teaching for both typical and atypically developing students (Kaufman \& Ireland, 2016). This important finding acknowledges the increasingly complex academic, emotional, and social needs of students and their families. Theories that guide interprofessional learning, for example relational learning (Browning $\&$ Solomon, 2006) and contact hypothesis theories (Hewstone \& Brown, 1986) address the critical nature of having students explore uncertainty, complexity, and ethical quandaries such as how teachers can meet these complex needs. Guidance from these theories facilitates meaningful, cross-perspectival experiences whereby future educators encounter vexing problems within the safety net of a collaborative learning environment.

\section{Implementing IPE in Undergraduate Education}

There is continuing debate as to the best time to introduce students to interprofessional collaborative learning. Novice learners typically have little knowledge of their chosen field of practice and likely little or no exposure to clinical experience. Without prior professional experience, IPE core competencies may seem abstract; students want to learn the nuts and bolts of their profession, not elusive concepts or 'soft skills' (Oandasan \& Reeves, 2005). Many feel they already know how to be on teams, having been involved in team-based sports or other group activities.

On the other side of the debate, proponents of early introduction to IPE view it as a pathway to building necessary skills that will mature as students advance in their studies (Pardue et al., 2018). Regardless of professional identity, IPE competencies promote productive and respectful communication that benefits the classroom and students' overall performance. Further, learning with diverse classmates sets the stage for reducing stereotypes and common misunderstandings of the roles that others will play on future teams. 
Table 1. Disciplinary Competencies for Interdisciplinary Practice

\begin{tabular}{|c|c|c|c|}
\hline $\begin{array}{l}\text { IPEC } \\
\text { Competency }\end{array}$ & Social Work (CSWE, 2015) & Occupational Therapy (AOTA, 2018) & $\begin{array}{l}\text { Education Standards } \\
\text { (InTASC, 2013)) }\end{array}$ \\
\hline $\begin{array}{l}\text { Competency 1: } \\
\text { Values and Ethics } \\
\text { for } \\
\text { Interprofessional } \\
\text { Practice }\end{array}$ & $\begin{array}{l}\text { EPAS 1: Demonstrate Ethical and Professional } \\
\text { Behavior: Social workers understand the value } \\
\text { base of the profession and its ethical standards. } \\
\text { Social Workers understand the role of other } \\
\text { professions when engaged in interprofessional } \\
\text { teams. }\end{array}$ & $\begin{array}{l}\text { ACOTE Standard B.1.5: Demonstrate an } \\
\text { understanding of the ethical and practical } \\
\text { considerations that affect the health and } \\
\text { wellness needs of those who are experiencing or } \\
\text { are at risk for social injustice, occupational } \\
\text { deprivation, and disparity in the receipt of } \\
\text { services. }\end{array}$ & $\begin{array}{l}\text { InTASC Standard } 99(\mathrm{o}) \text { : The teacher } \\
\text { understands the expectations of the profession } \\
\text { including codes of ethics, professional standards } \\
\text { of practice, and relevant law and policy. }\end{array}$ \\
\hline $\begin{array}{l}\text { Competency 2: } \\
\text { Knowledge of } \\
\text { Other's Roles and } \\
\text { Responsibilities }\end{array}$ & $\begin{array}{l}\text { EPAS 8: Intervene with Individuals, Families, } \\
\text { Groups, Organizations, and Communities. } \\
\text { Social workers value the importance of } \\
\text { interprofessional teamwork and communication } \\
\text { in interventions, recognizing that beneficial } \\
\text { outcomes may require interdisciplinary, } \\
\text { interprofessional, and inter-organizational } \\
\text { collaboration. }\end{array}$ & $\begin{array}{l}\text { ACOTE Standard B.4.28: Develop a plan for } \\
\text { discharge from occupational therapy services in } \\
\text { collaboration with the client and members of } \\
\text { the interprofessional team by reviewing the } \\
\text { needs of the client, caregiver, family, and } \\
\text { significant others; available resources; and } \\
\text { discharge environment. }\end{array}$ & $\begin{array}{l}\text { InTASC Standard } 10 \\
\text { 10(1): The teacher understands schools as } \\
\text { organizations within a historical, cultural, } \\
\text { political, and social context and knows how to } \\
\text { work with others across the system to support } \\
\text { learners. }\end{array}$ \\
\hline $\begin{array}{l}\text { Competency } 3: \\
\text { Interprofessional } \\
\text { Communication }\end{array}$ & $\begin{array}{l}\text { EPAS 8: Intervene with Individuals, Families, } \\
\text { Groups, Organizations, and Communities: } \\
\text { Social workers value the importance of inter- } \\
\text { professional teamwork and communication in } \\
\text { interventions, recognizing that beneficial } \\
\text { outcomes may require interdisciplinary, } \\
\text { interprofessional, and interorganizational } \\
\text { collaboration. }\end{array}$ & $\begin{array}{l}\text { ACOTE B.5.21 Effectively communicate and } \\
\text { work interprofessionally with those who } \\
\text { provide services to individuals, organizations, } \\
\text { and/or populations in order to clarify each } \\
\text { member's responsibility in executing an } \\
\text { intervention plan. }\end{array}$ & $\begin{array}{l}\text { InTASC Standard } 10 \\
\text { 10(n): The teacher knows how to work with } \\
\text { other adults and has developed skills in } \\
\text { collaborative interaction appropriate for both } \\
\text { face-to face and virtual contexts. }\end{array}$ \\
\hline $\begin{array}{l}\text { Competency 4: } \\
\text { Teams and } \\
\text { Teamwork }\end{array}$ & $\begin{array}{l}\text { EPAS 8: Intervene with Individuals, Families, } \\
\text { Groups, Organizations, and Communities: } \\
\text { Social workers value the importance of inter- } \\
\text { professional teamwork and communication in } \\
\text { interventions, recognizing that beneficial } \\
\text { outcomes may require interdisciplinary, inter- } \\
\text { professional, and inter-organizational } \\
\text { collaboration. }\end{array}$ & $\begin{array}{l}\text { ACOTE standard B.4.25: Demonstrate } \\
\text { knowledge of the principles of interprofessional } \\
\text { team dynamics to perform effectively in } \\
\text { different team roles to plan, deliver, and } \\
\text { evaluate patient- and population-centered care } \\
\text { as well as population health programs and } \\
\text { policies that are safe, timely, efficient, effective, } \\
\text { and equitable. }\end{array}$ & $\begin{array}{l}\text { InTASC Standard } 10 \\
10(\mathrm{e}) \text { : Working with school colleagues, the } \\
\text { teacher builds ongoing connections with } \\
\text { community resources to enhance student } \\
\text { learning and wellbeing. }\end{array}$ \\
\hline
\end{tabular}


Tenets from adult learning theory (Hewstone \& Brown, 1986; Kolb, 1984) offer a tiered approach that prepares students for learning together. It supports a developmental learning process, one that addresses cognitive readiness and promotes experiential, relational, and interactive teaching methods. Undergraduates are most familiar with lecture-style, single-discipline teaching methods and so the transition to more active engagement with students and faculty outside of their discipline can be challenging.

Undergraduates are in the formative stages of forging their professional identities and respond more favorably to active collaborative learning relevant to their own life experiences (Oandasan \& Reeves, 2005). IPE facilitation motivates students to learn about teamwork and associated competencies, and then learn "by doing" through activity-based experiences (Snyman \& Geldenhuys, 2019). It fosters students' self-confidence as they build their professional identities while simultaneously gaining skills to be productive members of present and future teams (Labrague et al., 2018; Lockeman et al., 2017). Faculty model and facilitate respectful communication and collaboration making it psychologically safe for students to be curious and critically explore each other's views and beliefs. In the process, students observe how other disciplines conceptualize and achieve common goals, noting how roles are similar, complementary, and distinctive from one another.

Students then apply what they have observed in active learning, for example, in simulated case studies. Simulation bridges classroom and experiential learning and is recommended as a modality for teaching interprofessional collaborative competencies (Labrague et al., 2018). Interprofessional simulation is specifically designed to engage students from two or more disciplines in an interactive experience based on relevant content and common learning outcomes (Decker et al., 2015).

Simulation affords students opportunities to enact roles and responsibilities based on scripted case scenarios with actors and other methods employing many of the principles of good practice in undergraduate education, including active learning and cooperation among students (Chickering \& Gamson, 1987). Case-based simulation is commonly used with graduate-level and professional students; less is known about the use of simulation with undergraduates. Emerging literature, however, has shown that undergraduate students participating in IPE simulation develop foundational communication skills, gain understanding of the cross-professional team, and build reflective and analytical skills (Hardisty et al., 2019). Framing IPE experiences conceptually as a starting point for skill development justifies early exposure to collaborative learning. When successful, students bring what they learn from introductory IPE activities into other experiential learning experiences, learn to communicate effectively, respect others, and value alternative perspectives. This benefits all educational experiences, offering a strong argument for early exposure to interprofessional experiences.

\section{Undergraduate Interprofessional Simulation Project}

Social work, pre-occupational therapy, and teacher education students were introduced to IPEC competencies through a shared interprofessional simulation project (ISP). Faculty collectively developed ISP content, activities, and learning objectives based on adult 
learning theories and IPE study findings. Learning objectives included: demonstration of cross-professional communication, use of collaborative teamwork skills, and recognition of the benefits and challenges of interprofessional practice. Faculty prompted students to be critical thinkers using disciplinary and interdisciplinary communication skills, and cultural responsiveness to assess the needs and challenges of the student, family, and school system.

The multi-step experience included: (a) classroom instruction on the topics of interprofessional education and communication and collaboration; (b) viewing a video of an exemplar interprofessional practice situation between the three professions (Year Two only); (c) introduction of the case study that would be the basis for the live simulation, including discipline specific instruction; (d) day-of-simulation activities, including an icebreaker and a pre-planning meeting among the disciplines; and (e) participation in the simulated meeting with the parent. Case scenarios were designed with students' cognitive development and learning levels in mind, each based upon a school-based scenario. Case studies integrated social determinants of health, calling students' attention to issues of diversity, economic disparities, and access to school and community resources within familial and community contexts. The case of Brian below illustrates a scenario used for the simulation sessions:

Brian, a 15-year-old biracial cisgender boy was diagnosed with mild autism at age three (3). Before a move, he lived in a racially and economically diverse community. His current school is in a mostly white, affluent district where there are high academic and extracurricular expectations and where parents are apprehensive to acknowledge their children's learning difficulties. Being a biracial youth with autism has made it very difficult for Brian to fit into his new environment. Early in his transition, Brian's mother, Lori, reached out to advocate for her son's special needs. She provided case files from the previous school district to the special education teacher, occupational therapist, and social worker. A meeting was scheduled for Lori to meet with these three professionals.

Students first worked within their discipline to discuss relevant information and then in interdisciplinary teams to discuss and prepare for the scheduled simulated meeting with the parent. Students were asked to discuss and reflect upon Brian's situation, their roles in working with him and his family, share thoughts about how to effectively communicate with Brian, the family and each other, and to ultimately develop an intervention plan. The ISP culminated in a live simulation with an actor playing Lori, Brian's mother, and debrief with students of the collaborative team.

The IPE simulation project used a team-based learning (TBL) model. Central to TBL is the design of cases that require effort to address the complexity and context of people's circumstances (Hrynchak \& Batty, 2012). Since the simulation was intended for undergraduates the case was set at moderate complexity to facilitate student success. Team goals included: (a) setting collaborative priorities, (b) addressing ethical and logistical dilemmas, (c) identifying sociocultural and personal factors that affect care plans, and (d) devising a viable team-based plan of intervention. For faculty, the simulation offered a venue to observe and evaluate students' proficiencies in these nascent areas of practice. 
For students, it provided an experience to gain a foundational "real life" understanding of the communication and collaboration skills required to engage in interprofessional practice.

Prior to the day of the ISP activity, students in each of the professions were given the common case study, along with discipline-specific information, supporting materials as well as relevant readings and resources. The goal of this pre-ISP activity was to build students' confidence in their disciplinary knowledge and identity. To illustrate, social work students were provided information about the availability of school and community resources, as well as child and family history collected by the child's previous school social worker. Pre-occupational therapy and education students were also provided information relevant to their roles in the school setting. ISP students discussed the case scenario with their classmates and course instructor in advance of the simulation.

In the first year, collaborative activities were scaffolded according to Kolb's (1984) experiential tiers throughout the semester. Following Kolb's guidance, instruction began in the classroom with didactics introducing the IPEC competencies and the intentions of interprofessional practice (Tier One). Next, students employed reflective observation to ponder the case scenario to reflect on from a critical standpoint (Tier Two). Faculty then encouraged students to critically expand their understanding of the case scenario and discuss strategies with classmates and the course instructor from the perspective of their discipline (Tier Three).

The simulation engaged students in active experimentation and application of new knowledge (Tier Four). It added elements of relational learning (Browning \& Solomon, 2006) whereby students were actively engaged in learning with and from each other, practicing together, tolerating differences and applying shared and diverse knowledge to problem-solve and make decisions together.

Immediately following the simulation, students debriefed the ISP with classmates and faculty using this opportunity to reflect upon their experience and observations. It concluded with students being sent an electronic recording of the team meeting and asked to complete two measures: (1) a self-assessment using the Collaboration Self-Assessment Tool (CSAT; Ofstedal \& Dahlberg, 2009); and (2) a self-designed interprofessional education perceptions questionnaire, both of which were administered as a pretest measures in their respective classrooms. A post-project survey was also administered. The CSAT and the self-designed questionnaire were subsequently replaced in Year Two with the Interprofessional Collaborator Assessment Rubric (ICAR) tool (Curran et al., 2011).

The second year followed a similar trajectory with slight changes in pedagogy and assessment based on feedback from the students' first-year evaluations. In addition to the tiered preparatory activities, students were shown a case scenario video in their disciplinespecific classes, one that was different from the selected case study used in the live simulation. The video showed a parent-school meeting between a social worker, teacher, and occupational therapist acted out by faculty with an actor playing the role of the parent. The purpose of this activity was twofold: first, it showed faculty modelling interprofessional competencies to address students lack of clinical experience to reference; second, it introduced students to the Interprofessional Collaborator Assessment (ICAR) 
(Curran et al., 2011). The students used the ICAR to rate the professionals depicted in the faculty-led video as a way to bring familiarity with the tool as they complete it as a selfassessment following their participation in the live simulation.

\section{Method}

A mixed methods approach was used to assess ISP outcomes. The University Institutional Review Board approved the project for the two-year period it was conducted. In Year 1, two quantitative assessment tools, the C-SAT (Ofstedal \& Dahlberg, 2009) and a self-designed interprofessional education perceptions tool were used. In Year 2, the ICAR (Curran et al., 2011) was used to evaluate undergraduate student's perception of competencies in areas of communication and collaboration. Both years, a post-project survey was administered to students. Overarching questions included: (1) Does early participation in an interprofessional simulation influence undergraduate students' selfassessment of their ability to collaborate and communicate?; and (2) How does early participation in an interprofessional simulation influence undergraduate students' understanding of interprofessional practice and its importance?

\section{Recruitment}

Students $(n=72)$ were recruited from social work, pre-occupational therapy, and teacher education in their sophomore year of study. In Year 1, there were 10 surveyed groups, each with 4 students, with a total of 40 students; in Year 2, there were 8 surveyed groups, each with 4 students, with a total of 32 students. ISP participation was a course requirement integrated into the curriculum for all disciplines. Participants were randomly assigned to survey groups composed of at least one representative from each discipline.

\section{Data Collection}

In the first year, data were collected from two quantitative assessment tools, the CSAT (Ofstedal \& Dahlberg, 2009) and a self-designed tool to measure interprofessional education perceptions. Qualitative and quantitative data were collected via a post-project survey developed by the faculty (see addendum). The post-project survey was a qualitative measure using open-ended questions and Likert scale ratings to assess communication and collaboration skills and students' understanding of interprofessional practice.

In Year 2, quantitative data were collected with the ICAR (Curran et al., 2011), a competency-based rubric that assesses performance in communication, collaboration, roles and responsibilities, collaborative patient/family centered approach, and conflict management during interprofessional encounters (Curran et al., 2011). This tool was chosen for its interprofessional focus and because the subtests could be used separately. For the purposes of the ISP, only the communication and collaboration subtests were used. Year 2 students also completed the post-project survey, which was revised slightly to align with the ICAR instrument subtests of collaboration and communication.

To address the anticipated inflation of students' self-assessment, the ICAR was introduced to students after they viewed the video of a school-based interprofessional team meeting with a parent acted out by a paid actor and faculty with several years of practice 
experience. This video modeled a team meeting, which students could use as a reference to more accurately assess their own ability after participating in the live simulation. Instead of the pre/post-test study design, faculty decided to review videos of the student team meetings and rate them using the ICAR which would then be used as a comparison to students' self-assessment. Difficulty in scoring arose when the faculty could not reach consensus on how to define the rating scale criteria used in the ICAR (i.e., minimal, developing, competent, mastery). The central question was whether to rate at students from the interprofessional skill level they should possess at this early stage of development or from a much more refined stage where mastery in their disciplinary field could be demonstrated. This discrepancy was not anticipated and because a shared understanding of the criteria could not be reached, the data were not analyzed as intended.

\section{Data Analysis}

In Year 1, students rated their perception of collaboration by completing pre and posttests before and after the simulation. A significance level of .05 was used to measure the difference in the pre and post-test scores.

In Year 2, students rated perception of collaboration and communication via the ICAR. The following represents the average ICAR scores of students' self-assessment following the live simulation and demonstrates their inflated self-efficacy in the areas rated. A scale of 1-4 is used on the ICAR with 4 representing "mastery": (1) Respectful Communication included three subsets with average scores between 3.17-3.41; (2) Communication Strategies included 4 subsets with average scores between 2.65 and 3.35; (3) Collaborative Relationship had 1 subset with an average score of 3.38; (4) Integration of Information from others had 1 subset with an average score of 3.03; and (5) Information Sharing included 2 subsets with an average score between 3.06 and 3.08 .

\section{Figure 1. Change in Perception of Communication and Collaboration}

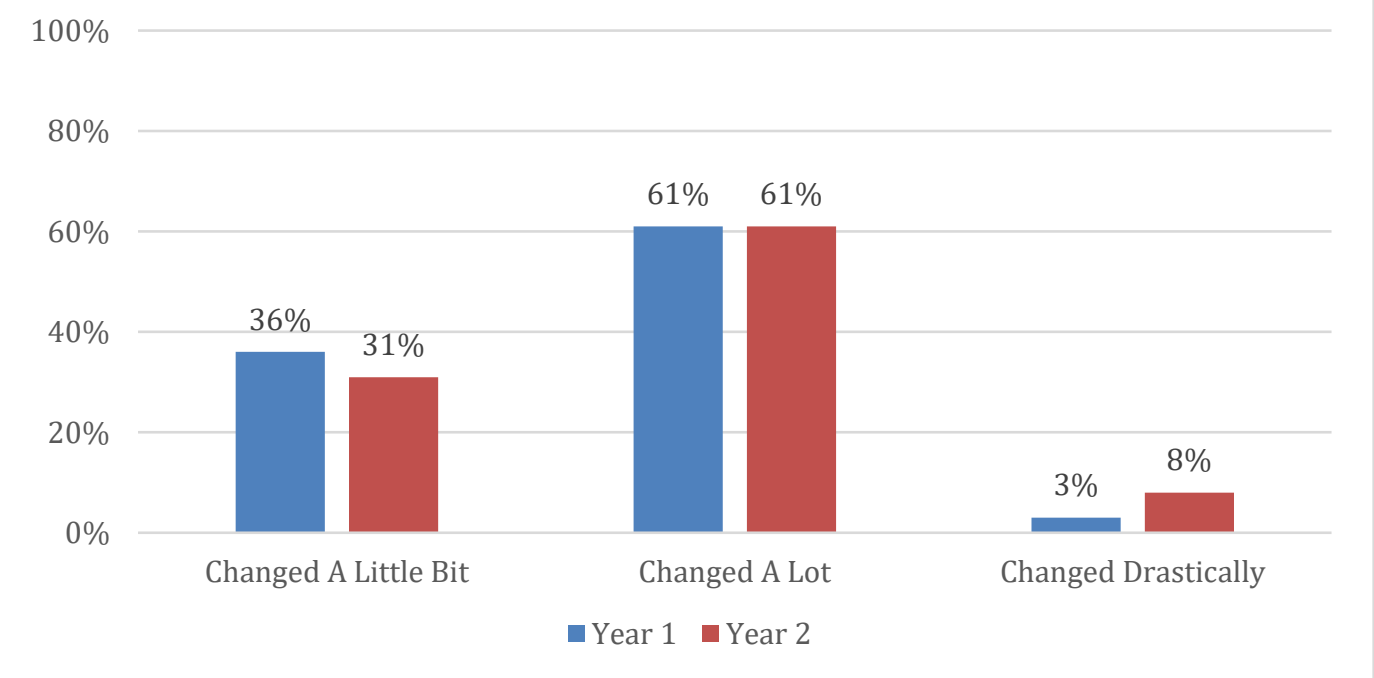


Students each completed a post-project survey consisting of Likert scale and openended questions via an online survey tool. Data culled from the Likert scale questions showed $61.11 \%$ of students in Year 1 (Y1) and 61.0\% of students in Year 2 (Y2) believed that their perception of communication and collaboration "changed a lot." Of students reporting, 2.7\% (Y1) and 8.5\% (Y2) believe their perception of communication and collaboration "changed drastically." See Figure 1.

Qualitative analysis utilized coding, descriptive analysis, and thematic analysis of the data related to the central ideas, or codes extracted from the data collection (Atkinson, 2005). Survey results were analyzed using a process of thematic analysis completed by three of the team members. The project team independently reviewed student responses to the open-ended questions and grouped responses by similar content. Next, the project team convened to compare their individual analysis, organize the responses, and analyze the response groups for codes. The student responses were then coded and used to develop themes that answered the two overarching questions that drove this project. See Table 2.

Themes that emerged from the students' comments related to Question 1: "Does early participation in an interprofessional simulation influence undergraduate students' selfassessment of their ability to collaborate and communicate?" included: (1) increased confidence in the ability to communicate and collaborate; and (2) recognition of skills needed to communicate and collaborate effectively.

Themes that emerged related to Question 2: "How does early participation in an interprofessional simulation influence undergraduate students' understanding of interprofessional practice and its importance?" reflected the following: (1) recognition of benefits of interprofessional practice; and (2) clarified understanding of roles.

Table 2. Qualitative Themes Regarding Communication and Interprofessionalism

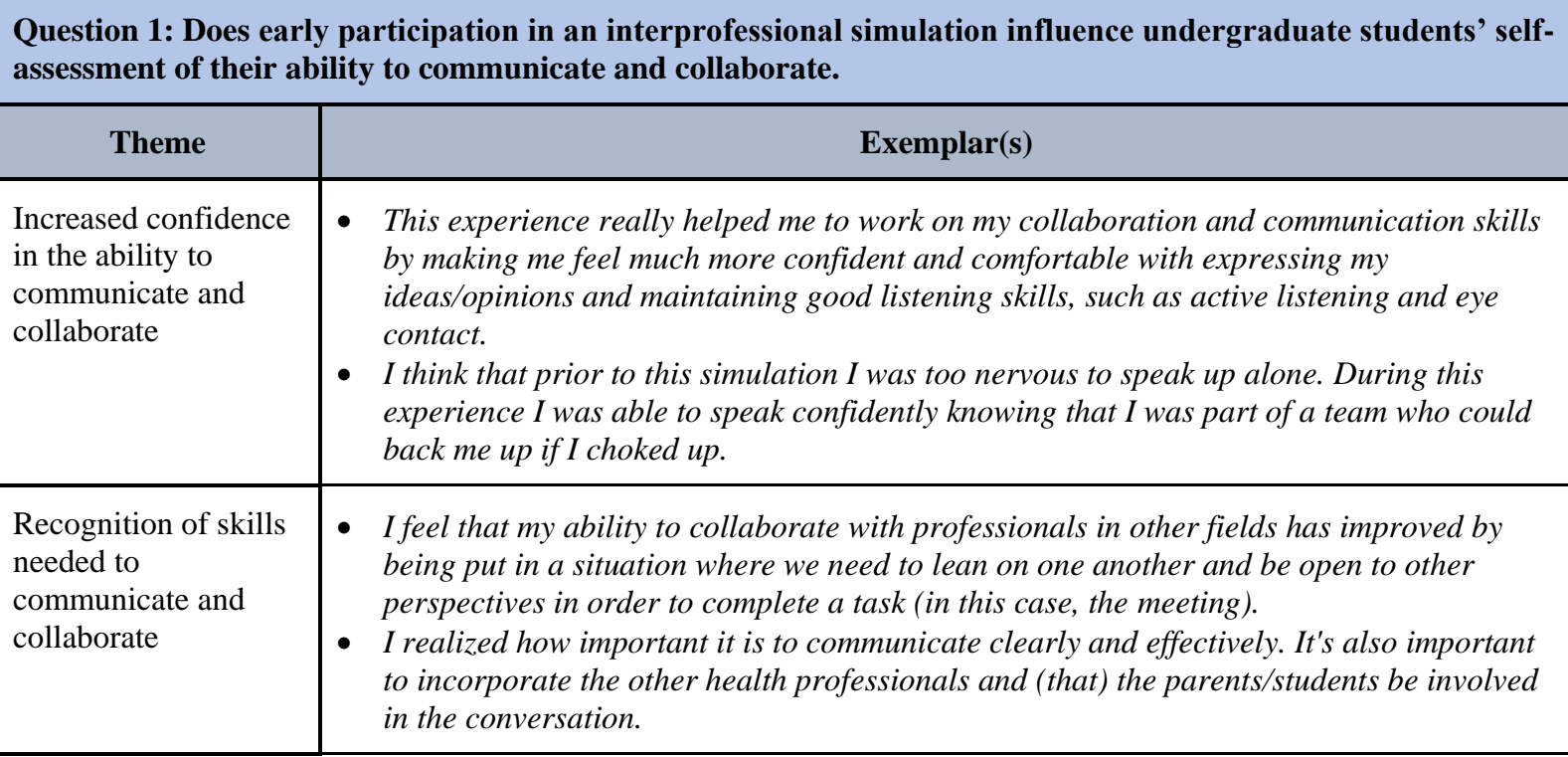




\begin{tabular}{|c|c|}
\hline $\begin{array}{l}\text { Recognition of } \\
\text { benefits of } \\
\text { interprofessional } \\
\text { collaboration }\end{array}$ & $\begin{array}{l}\text { - I think having the time to plan the meeting with other people and then carry out the plan } \\
\text { was very beneficial. } \\
\text { - I learned that you have to work within a team in order to complete a goal. I also learned } \\
\text { that since we are working towards a common goal, that it is essential for professionals } \\
\text { to work together. I do not think anything would be accomplished if the different } \\
\text { professions did not work together. }\end{array}$ \\
\hline $\begin{array}{l}\text { Clarified } \\
\text { understanding of } \\
\text { roles }\end{array}$ & $\begin{array}{l}\text { - This experience showed me the role of other professionals and the role of my profession } \\
\text { and how we can all work together for a common goal. } \\
\text { - I think this experience helped me to see the various ways different professions interact } \\
\text { with each other and how important this is. The information I was given was very } \\
\text { different from the other team members and when we discussed this, it revealed a lot } \\
\text { more about [simulation student] than I knew. It is important for everyone to share what } \\
\text { they know and collaborate in order to develop a plan that is going to work for him. } \\
\text { - I think it is important working with other professions because a lot of people are not able } \\
\text { to work in other professions until they are in their field. So, getting that experience we } \\
\text { sort of got a head start. } \\
\text { The idea of using information from each profession was very insightful. Before the } \\
\text { simulation I had no idea of what a social worker could offer to a student with autism and } \\
\text { I learned a lot about how we could work together using the child's interests. }\end{array}$ \\
\hline
\end{tabular}

\section{Limitations}

Because of the unique combination of education, social work, and OT in the school setting, it was challenging to identify a tool to measure school-related collaborative competencies for this specific group of undergraduate students. One limitation was that the quantitative self-assessment tools used, the C-SAT, self-designed interprofessional perceptions questionnaire and ICAR, were designed for graduate level education and the health care setting.

During Year 1 of the project, the C-SAT, a validated assessment tool, was used to assess communication and collaboration and the self-designed interprofessional perceptions questionnaire was used to assess the students' perceptions of IPE. The team was aware that a self-designed assessment tool could not be validated and the data would not be reliable, however it was used to gain insight into the impact the activities had on students' interprofessional education perceptions. A deeper analysis of the C-SAT results raised questions of the reliability because (1) it was normed on a graduate population, (2) high measures were likely the results of students' inflated self-efficacy, (3) undergraduates are at the beginning stages of this type of collaboration, and (4) this single incidence was their only experience participating in a collaborative interprofessional activity.

In Year 2, the ICAR was selected because its adaptable subtests allowed for targeted assessment of the project aims. The communication and collaboration perception subtests were selected as measures as they closely aligned with the ISP setting, goals, and our undergraduate population. Analysis of the data again raised concerns regarding the developmental stage of undergraduates' professional growth and ability to self-assess. For 
example, the ICAR uses a 4-point scale, with 4 representing mastery and average scores on all subsets were between 2.65 and 3.38. Many students rated themselves higher than seemed reasonable in these domains. According to other studies, this finding is not unusual (Pardue, 2013; Ruebling et al., 2014).

The post-project qualitative survey tool was designed for the ISP project and thus poses a limitation as it cannot be generalized to other undergraduate simulation activities or to other populations of students. Further, it was only administered post activity and therefore changes in attitudes and behaviors cannot be effectively measured.

Despite the perceived and practical limitations of the quantitative and qualitative assessment instruments, the pedagogical updates to Year 2 offered positive steps towards identifying methods for teaching students to observe and evaluate the skills of interprofessional teams, and understanding of undergraduate interprofessional learning in the future.

\section{Discussion}

The use of interprofessional simulation in undergraduate education is gaining momentum, though research validating its outcomes are sparse. This project explored how early participation in the ISP influenced undergraduate students' self-assessment of their ability to collaborate and communicate across disciplines, and their understanding of interprofessional practice and its importance in their chosen fields. Collaborative learning with social work, teacher education, and pre-occupational therapy students is relatively unique, as IPE has historically focused on student preparation in healthcare at the graduate level. The 2016 IPEC update encouraged the expansion of intentional team preparation to fields beyond healthcare underscoring the intersectionality of practices necessary to improve overall health. The report states its aims ".... to prepare professionals in health and other fields ... for professional activities that impact population health, and to work together across disciplines, organizations, and sectors on innovative strategies to improve population health." (IPEC, 2016, p. 7).

The simulation immersed students in a learning activity where they were asked to actively listen, gather information, and then strategize ways to address the client's needs. Student discussion was guided by interprofessional facilitation methods, Kolb's four tier experiential adult learning model, and elements of contact hypothesis and relational theories (Browning \& Solomon, 2006; Hewstone \& Brown, 1986; Hrynchak \& Batty, 2012; Kolb, 1984; Reeves \& Hean, 2013). Faculty prompted students to engage in casebased critical and contextual thinking inclusive of the values and roles of their professions. They were further directed to consider the attitudes and skills needed for teamwork and for building relationships with each other.

Student comments in the post-simulation survey demonstrated a burgeoning understanding of collaborative practice and its complexities. Students gained a deeper understanding of how effective communication is inextricably connected to successful collaboration and an appreciation for the distinct roles and perspectives of their future discipline, and that of others. They were also inspired by the opportunity to collaborate 
through IPE practices early on in their education; likely increasing trust in the educational process and engagement in future IPE endeavors.

The use of an intentional, scaffolded approach to the live simulation activity was essential given that undergraduate students have little if any understanding of their own profession, let alone how professionals in other fields interact with and rely on others. But undergraduates certainly know about teamwork, most of them having participated in sports, band, and other activities that require a coordinated team effort. Offering this opportunity early in students' progression allows them to draw upon what they already know about success and failure in teamwork and creates a foundation for understanding the broader concept of collaboration. Although students consistently overestimate their team prowess, gaining confidence in their individual and collaborative expertise has its fair share of benefits.

Introductory collaborative learning experiences, especially for those at the beginning of their undergraduate professional programs, should be viewed as the starting point for future learning activities. As one ISP student stated: "The experience taught me important and effective communication skills that a textbook simply can't teach." Another student referred to their ISP experience as getting a "head start" on learning to work collaboratively across professions. The relational aspect of the experience was highly valued. Students felt supported by each other and comfortable asking questions, risking critique, and learning from each other, key aspects of Browning and Solomon's (2006) relational learning model.

For generalist social work students, the ISP fulfilled CSWE's requirement to demonstrate competence "in real or simulated practice activities situations" (CSWE, 2015). Levels of competency build over time as new concepts are continually introduced throughout the curriculum giving students multiple opportunities to achieve EPAS competencies in preparation of interprofessional and interdisciplinary practice. Social work students' reflective practices complement knowledge increasing their affective learning capacities.

Like social work, OTs practice across clinical and community settings working in interprofessional and interdisciplinary teams. However, most interprofessional learning in social work and pre-occupational therapy curriculum focuses on clinically-based medical case scenarios, not situations encountered in community-based settings such as schools. There remains limited research on the benefits and challenges of these common collaborations (Bose \& Hinojosa, 2008). Moreover, institutions housing these health professions have not capitalized on learning opportunities that would significantly improve teamwork in schools, within special education, and in other educational settings. To be effective practitioners, OTs, social workers, and educators need more exposure to each other's roles and responsibilities and to specific training that incorporates interprofessional competencies.

\section{Implications}

Implications derived from this two-year interprofessional simulation project apply to both research and higher education. Longitudinal studies looking at the benefits and challenges of introducing undergraduates to IPE pedagogy would be a logical next step. 
We suggest that undergraduate and graduate IPE experiences in non-health-related collaborative learning environments be explored. Specifically, opportunities to create and evaluate collaborative learning opportunities with students in professions like social work, OT, and teacher education who naturally work together in K-12 settings should be taken. Creation of continuing education and training for teacher education teams in interprofessional collaboration is recommended to support interventions addressing the intersectional and complex needs of children, families, and communities. This work represents a new frontier for infusing collaborative competencies and practices in school settings and other fields where professions work together.

Measurement tools that are reflective of undergraduate collaborative competency and those specific to fields outside of healthcare, for example school settings, corrections facilities, and childcare, need further exploration and development. Instruments inclusive of the roles and responsibilities within these environments would improve the validity of data gathered from studies like the ISP and conforms to the intentions of the revised 2016 U.S. IPEC Core Competencies.

\section{Conclusion}

The Merriam-Webster (2020) definition of jumpstart speaks to imparting fresh and renewed energy to something that needs a boost. It utilizes the language of connection as a source of reenergizing something that may be suffering from overuse or in need of revival. The ISP provided fresh energy to undergraduate engagement in collaborative learning through experiential, simulated activities. It provided important insight and experience with an intentionally designed, multi-tiered, theory-informed interprofessional learning experience. Most student participants found the ISP positively changed their initial perceptions of collaboration and communication. Students encountered the rigors of engaging in collaborative practice and gained confidence in their disciplinary and collaborative abilities. Overall, they described the ISP as a productive, pre-clinical learning experience that gave them early insight into "what it's like working with other professionals."

IPE promotes connected learning to improve knowledge, skills, and attitudes with the long-term goal that these assets are fully actualized when students graduate into their professional lives. The author team agrees with advocates who view early introduction to IPE as a thoughtful and scaffolded pathway to skills that will mature as students advance in their studies and develop professional identities and capacities to be excellent team players. We ask, why wouldn't every professional field benefit from employees fully trained in cross-professional communication, collaboration, respectfulness, and openness to others perspectives? We will continue to build and evaluate this model and are happy to share our progress with those from other interested institutions.

\section{References}

American Occupational Therapy Association [AOTA]. (2011). Occupational therapy services in early childhood and school-based settings. American Journal of Occupational Therapy, 65 (Suppl.), S46-S54. https://doi.org/10.5014/ajot.2011.65s46 
AOTA. (2015). Importance of interprofessional education in occupational therapy curricula. American Journal of Occupational Therapy, 69(Suppl. 3), S1-S8. https://doi.org/10.5014/ajot.2015.696s02

AOTA. (2015). Occupational therapy code of ethics. American Journal of Occupational Therapy, 69(Suppl. 3), 1-8. https://doi.org/10.5014/ajot.2015.696S03

AOTA. (2018). 2018 Accreditation council for occupational therapy education standards and interpretive guide. https://www.aota.org/ /media/Corporate/Files/EducationCareers/Accredit/StandardsR eview/2018-ACOTE-Standards-Interpretive-Guide.pdf

Atkinson, P. (2005). Qualitative research. Unity and diversity. Qualitative Social Research, 6(3), 1-15.

Bose, P., \& Hinojosa, J. (2008). Interacting with teachers in inclusive early childhood classrooms. American Journal of Occupational Therapy, 62, 289-297. https://doi.org/10.5014/ajot.62.3.289

Bronstein, L. R. (2003). A model for interdisciplinary collaboration. Social Work, 48(3), 297-306.

Browning, D. M., \& Solomon, M. Z. (2006). Relational learning in pediatric palliative care: Transformative education and the culture of medicine. Child and Adolescent Psychiatric Clinics of North America, 15, 795-815. https://doi.org/10.1016/j.chc.2006.03.002

Chickering, A. W., \& Gamson, Z. F. (1987). Seven principles for good practice in undergraduate education (special insert). AAHE Bulletin, 1987(3), 2-6. https://files.eric.ed.gov/fulltext/ED282491.pdf

Clarke, L.W., Box, E., \& Cigna, O. (2019, May). "It takes a village” Understanding interprofessional collaboration in K-12 schools. Presented at the University of New England Spring Research Symposium, Biddeford, ME.

Cohen Konrad, S. C., Cavanaugh, J., Hall, K., Rodriguez, K., \& Pardue, K. T. (2017). A five-session interprofessional team immersion program for health professions students. Journal of Interprofessional Education and Practice, 6, 49-54. https://doi.org/10.1016/j.xjep.2016.12.007

Cox, M., Cuff, P., Brandt, B., Reeves, S., \& Zierler, B. (2016). Measuring the impact of interprofessional education on collaborative practice and patient outcomes, Journal of Interprofessional Care, 30(1), 1-3. https://doi.org/10.3109/13561820.2015.1111052

Council of Chief State School Officers. (2013, April). Interstate teacher assessment and support consortium InTASC model core teaching standards and learning progressions for teachers 1.0: A resource for ongoing teacher development. Washington, DC.

Council on Social Work Education. (2015). Educational policy and accreditation standards. Author. https://www.cswe.org/getattachment/Accreditation/AccreditationProcess/2015-EPAS/2015EPAS Web FINAL.pdf.aspx 
Curran, V., Hollett, A., Casimiro, L. M., Banfield, V., Hall, P., Lackie, K., Oandasan, I., Simmons, B., \& Wagner, S. (2011). Development and validation of the interprofessional collaborator assessment rubric (ICAR). Journal of Interprofessional Care, 25(5), 339-344. https://doi.org/10.3109/13561820.2011.589542

D'Agostino, C. (2013). Collaboration as an essential school social work skill. Children \& Schools, 35(4), 248-251. https://doi.org/10.1093/cs/cdt021

Decker, S. I., Anderson, M., Boese, T., Epps, C., McCarthy, J., Motola, I., \& Scolaro, K. (2015). Standards of best practice: Simulation standard VIII: Simulation-enhanced interprofessional education (Sim-IPE). Clinical Simulation in Nursing, 11, 293-297. https://doi.org/10.1016/j.ecns.2015.03.010

Gray, J. M., Coker-Bolt, P., Gupta, J., Hissong, A., Hartmann, K., \& Kern, S. B. (2015). Importance of interprofessional education in occupational therapy curricula. American Journal of Occupational Therapy, 69(S3), 1-14. https://doi.org/10.5014/ajot.2015.696s02

Halle, A. D., Kaloostain, C., \& Sevens, G. D. (2019). Brief report-Occupational therapy student learning on interprofessional teams in geriatric primary care. American Journal of Occupational Therapy, 73(5), 1-7. https://doi.org/10.5014/ajot.2019.037143

Hardisty, J., O’Neil, H., O'Connell, J., Hancock, R., Lucas, R., \& Parkin, L. (2019). Simulating complexity: Providing undergraduate students with exposure in early clinical training to the multidisciplinary management of frail older people. $B M J$ Simulation \& Technology Enhanced Learning, 5(2), 1-6. https://doi.org/10.1136/bmjstel-2017-000258

Hewstone, M., \& Brown, R. J. (1986). Contact is not enough: An intergroup perspective on the Contact Hypothesis. In M. Hewstone \& R. J. Brown (Eds.), Contact and conflict in intergroup encounters (pp. 1-44). Oxford: Blackwell. https://doi.org/10.1177/002087288803100210

Howell, D. M., \& Cleary, K. K., (2001). Benefits of an interdisciplinary approach: A case of collaboration. Physical and Occupational Therapy in Geriatrics, 20(1), 73-83. https://doi.org/10.1080/j148v20n01 06

Hrynchak, P., \& Batty, H. (2012). The educational theory basis of team-based learning. Medical Teacher, 34, 796-801. https://doi.org/10.3109/0142159x.2012.687120

International Federation of Social Workers [IFSW]. (2018). Statement of ethical principles. http://ifsw.org/policies/statement-of-ethical-principles/

Interprofessional Education Collaborative. (2016). Core competencies for interprofessional collaborative practice: 2016 update. Washington, DC: Interprofessional Education Collaborative. https://hsc.unm.edu/ipe/resources/ipec2016-core-competencies.pdf

Johnson, C. E., (2017). Understanding interprofessional collaboration: An essential skill for all practitioners. OT Practice, 22(11), 1-8. 
Merriam Webster Online. (2020). Jumpstart. https://www.merriamwebster.com/dictionary/jump-start

Kaufman, D., \& Ireland, A. (2016). Enhancing teacher education with simulations. Tech Trends, 60, 260-267. https://doi.org/10.1007/s11528-016-0049-0

Kolb, D. A. (1984). Experiential learning: Experience as the source of learning and development. Englewood Cliffs, NJ: Prentice Hall.

Labrague, L. J., McEnroe-Petitte, D. M., Fronda, D. C., \& Obeidata, A. A. (2018). Interprofessional simulation in undergraduate nursing program: An integrative review. Nurse Education Today, 67, 46-55. https://doi.org/10.1016/j.nedt.2018.05.001

Lockeman, K. S., Appelbaum, N. P., Dow, A. W., Orr, S., Huff, T. A., Hogan, C. J., \& Queen, B. A. (2017). The effect of an interprofessional simulation-based education program on perceptions and stereotypes of nursing and medical students: A quasiexperimental study. Nurse Education Today, 58, 32-37.

https://doi.org/10.1016/j.nedt.2017.07.013

McFadyen, A., Webster, V., Maclaren, W., \& O'Neill, M. (2010). Interprofessional attitudes and perceptions: Results from a longitudinal controlled trial of preregistration health and social care students in Scotland. Journal of Interprofessional Care, 24, 549-564. https://doi.org/10.3109/13561820903520369

McMahon, T., Ward, N., Kline Pruett, M., Davidson, L., \& Griffith, E. (2012). Building full-service schools: Lessons learned in the development of interagency collaboratives, Journal of Educational and Psychological Consultation, 11(1), 65-92. https://doi.org/10.1207/s1532768xjepc1101_05

Mellor, R., Cottrell, N., \& Moran, M. (2013). "Just working in a team was a great experience..."-Student perspectives on the learning experiences of an interprofessional education program. Journal of Interprofessional Care, 27, 292-297. https://doi.org/10.3109/13561820.2013.769093

Morrell, B. L. M., Nichols, A. M., Voll, C. A., Hetzler, K. E., Toon, J., Moore, E. S., Moore, S. M., Kemery, S. R., \& Carmack, J. N. (2018). Care across campus: Athletic training, nursing, and occupational therapy student experiences in an interprofessional simulation. Athletic Training Education Journal, 13(4), 332-339. https://doi.org/10.4085/1304332

Moyers, P. A., Guthrie, P. L., Swan, A. R., \& Sathe, L. A. (2014). Interprofessional evidence-based clinical scholar program: Learning to work together. American Journal of Occupational Therapy, 68, S23-S31. https://doi.org/10.5014/ajot.2014.012609

National Association of Social Workers [NASW]. (2017). NASW Standards for School Social Work Services. https://www.socialworkers.org/LinkClick.aspx?fileticket=eLUS2JLweG8\%3d\&portali $\underline{\mathrm{d}=0}$

NASW. (2017). NASW code of ethics. Author. https://www.socialworkers.org/About/Ethics/Code-of-Ethics/Code-of-Ethics-English 
Oandasan, I., \& Reeves, S. (2005). Key elements for interprofessional education: Part 1: The learner, the educator and the learning context. Journal of Interprofessional Care, 19(Suppl. 1), 21-38. https://doi.org/10.1080/13561820500083550

Ofstedal, K., \& Dahlberg, K. (2009). Collaboration in student teaching: Introducing the collaboration self-assessment tool. Journal of Early Childhood Teacher Education, 30:1, 37-48. https://doi.org/10.1080/10901020802668043

Pardue, K. T. (2013). Not left to chance: Introducing an undergraduate interprofessional education curriculum. Journal of Interprofessional Care, 27, 98-100. https://doi.org/10.3109/13561820.2012.721815

Pardue, K. T., Cohen Konrad, S., \& Dunbar, D. M. (2018). Weaving interprofessional education into nursing curricula. In M. Oermann, J. DeGagne, \& B. Phillips (Eds.), Teaching in nursing and the role of the educator (pp. 135-152). New York: Springer Publishing Company. https://doi.org/10.1891/9780826140142.0008

Reeves, S., \& Hean, S. (2013). Why we need theory to help us better understand the nature of interprofessional education, practice and care, Journal of Interprofessional Care, 27(1), 1-3. https://doi.org/10.3109/13561820.2013.751293

Rubin, M., Cohen Konrad, S., Nimmagadda, J., Scheyet, A., \& Dunn, K. (2018). Social work and interprofessional education: integration, intersectionality, and institutional leadership. Social Work Education, 38, 17-33. http://dx.doi.org/10.1080/02615479.2017.1363174

Ruebling, I., Pole, D., Breitbach, A. P., Frager, A., Kettenbach, G., Westhus, N., Kienstra, K., \& Carlson, J. (2014). A comparison of student attitudes and perceptions before and after an introductory interprofessional education experience. Journal of Interprofessional Care, 28(1), 23-27. https://doi.org/10.3109/13561820.2013.829421

Shoemaker, M. J., Platko, C. M., Cleghorn, S. M., \& Booth, A. (2014). Virtual patient care: An interprofessional education approach for physician assistant, physical therapy, and occupational therapy students. Journal of Interprofessional Care, 28(4), 365-367. https://doi.org/10.3109/13561820.2014.891978

Snyman, S., \& Geldenhuys, M. (2019). Exposing an interprofessional class of first years to an underserved community contributed to students' contextualisation of the determinants of health. Journal of interprofessional Care, 33(3), 280-290. https://doi.org/10.1080/13561820.2019.1566219

Stone, S. I., \& Charles, J. (2018). Conceptualizing the problems and possibilities of interprofessional collaboration in schools. Children and Schools, 40(3), 185-192. https://doi.org/10.1093/cs/cdy011

World Health Organization. (2010). Framework for action on interprofessional education and collaborative practice. https://apps.who.int/iris/handle/10665/70185

Author note: Address correspondence to Cyndi Amato, School of Social Work, University of New England, Decary 410, ME 04005. Email: camato@une.edu 
Appendix. Post Project Survey Questions - Years One and Two

\begin{tabular}{|c|c|}
\hline Year One Survey & Year Two Survey \\
\hline 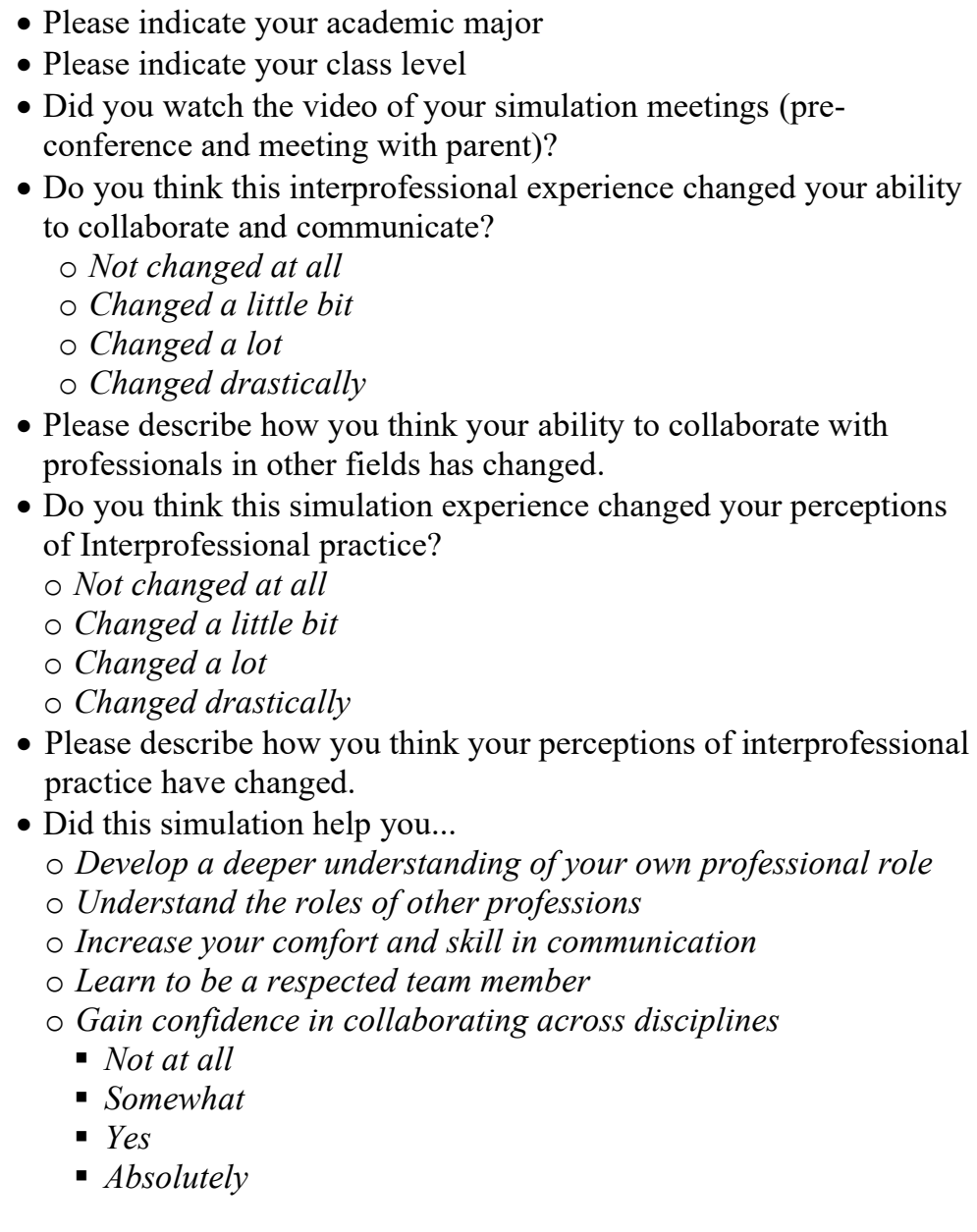 & $\begin{array}{l}\text { - Please indicate your academic major } \\
\text { - Please indicate your class level } \\
\text { - Do you think this interprofessional experience changed your ability to } \\
\text { collaborate and communicate? } \\
\text { o Not changed at all } \\
\text { o Changed a little bit } \\
\text { o Changed a lot } \\
\text { O Changed drastically } \\
\text { - Did the activities in this experience help you... } \\
\text { O Improve your respectful communication skills? } \\
\text { O Acquire and/or improve effective communication strategies? } \\
\text { o Develop collaborative relationships? } \\
\text { O Integrate information shared by others? } \\
\text { O Share information with others? } \\
\text { - If you think this experience helped change your skills, perceptions, values of } \\
\text { IPE in other ways, please describe them here. If not, leave this blank. } \\
\text { - Do you think this simulation experience changed your perceptions of } \\
\text { Interprofessional practice? } \\
\text { o Not changed at all } \\
\text { O Changed a little bit } \\
\text { O Changed a lot } \\
\text { o Changed drastically } \\
\text { - Did the activities in this experience help you... } \\
\text { o Understand the value of interprofessional teams including improving } \\
\text { services for students and reducing costs? } \\
\text { O Understand the role of you and your peers on an interprofessional team? } \\
\text { o Enhance your educational experience and ability to work on an } \\
\text { interprofessional team? } \\
\text { o Believe students from different educational-related fields should be } \\
\text { educated to establish collaborative relationships? } \\
\text { - Did not help }\end{array}$ \\
\hline
\end{tabular}




\begin{tabular}{|c|c|}
\hline $\begin{array}{l}\text { - How interested would you be in participating in this type of } \\
\text { simulation experience again? } \\
\text { ○ Not at all interested } \\
\circ \text { Somewhat interested } \\
\circ \text { Interested } \\
\circ \text { Absolutely interested } \\
\text { - How important do you think it is for other students in your same } \\
\text { course of study to participate in this simulation experience? } \\
\text { ○ Not at all important } \\
\text { ○ Somewhat important } \\
\circ \text { Important } \\
\circ \text { Very Important } \\
\text { - Any other comments that you would like to share with us? }\end{array}$ & $\begin{array}{l}\text { - Somewhat helped } \\
\text { - Helped a lot } \\
\text { - If you think this this skill/knowledge/viewpoint } \\
\text { collaboration skills in other ways, please describe them here. If not, leave } \\
\text { this blank. } \\
\text { - Consider how your skills have improved as a result of this experience. } \\
\text { Please indicate how valuable you found each part of the experience. } \\
\text { ○ Mini lecture on IPE } \\
\text { ○ Mini lecture on communication and collaboration } \\
\text { ○ Watching the simulated meetings on video } \\
\text { ○ Discussion of the case study ahead of simulation } \\
\text { ○ Simulation experience } \\
\text { ○ Watching your own video and reflecting on your communication and } \\
\text { collaboration skills } \\
\text { - Not valuable at all } \\
\text { - Somewhat valuable } \\
\text { - Very valuable } \\
\text { - How important do you think it is for other students in your same course of } \\
\text { study to participate in this simulation experience? } \\
\text { ○ Not at all important } \\
\text { ○ Somewhat important } \\
\text { ○ Important } \\
\text { ○ Very Important } \\
\text { - Please indicate if you participated in the simulation experience last year. } \\
\text { - If you have participated in the experience before, did you find it helpful to } \\
\text { participate in it again? } \\
\text { - Please elaborate on why you found participating in the experience again } \\
\text { helpful or not. } \\
\text { - How interested would you be in participating in this type of simulation } \\
\text { experience again? } \\
\text { - Any other comments that you would like to share with us? }\end{array}$ \\
\hline
\end{tabular}

